\title{
Computer-Aided Design of Tubular Travelling-Wave Arrays
}

\section{Arnbak, Jens}

\section{Published in:}

2nd European Microwave Conference

Link to article, DOI:

10.1109/EUMA.1971.331465

Publication date:

1971

\section{Document Version}

Publisher's PDF, also known as Version of record

Link back to DTU Orbit

\section{Citation (APA):}

Arnbak, J. (1971). Computer-Aided Design of Tubular Travelling-Wave Arrays. In 2nd European Microwave Conference (Vol. Volume 1, pp. 1-4). IEEE. https://doi.org/10.1109/EUMA.1971.331465

\section{General rights}

Copyright and moral rights for the publications made accessible in the public portal are retained by the authors and/or other copyright owners and it is a condition of accessing publications that users recognise and abide by the legal requirements associated with these rights.

- Users may download and print one copy of any publication from the public portal for the purpose of private study or research.

- You may not further distribute the material or use it for any profit-making activity or commercial gain

- You may freely distribute the URL identifying the publication in the public portal

If you believe that this document breaches copyright please contact us providing details, and we will remove access to the work immediately and investigate your claim 
COMPUTER-AIDED DESIGN OF TUBULAR TRAVELLING-WAVE ARRAYS

Jens Arnbak

Laboratory of Electromagnetic Theory

Technical University of Denmark, DK-2800 Lyngby

\section{SUMMARY}

Tubular antennas derived from arrays of gaps in circular waveguide can be designed by a computer program operating on the gap interspacings and gap widths, and taking into account realistic features like external mutual coupling and finite tube wall thickness. Linearly polarised radiation makes these antennas candidates for radar applications and for microwave television transmitters.

\section{INTRODUCTION}

Radar detection of targets in a sea clutter environment can often be improved by ensuring strictly horizontal polarisation. With the common inclined-slot array in rectangular waveguide, this is impossible to approach satisfactorily without applying an additional polarisation filter. No extra means are, however, necessary with slot arrays milled in dielectric-filled circular or coaxial waveguide, if the slots are extended along the entire circumference of a guide operated in a rotation-invariant TMmode. Suitable directive properties in the elevation plane of this linear gap array can be obtained from a cylindrical reflector behind the line source, as shown in Fig. 1 for an $\mathrm{X}$-band radar antenna.

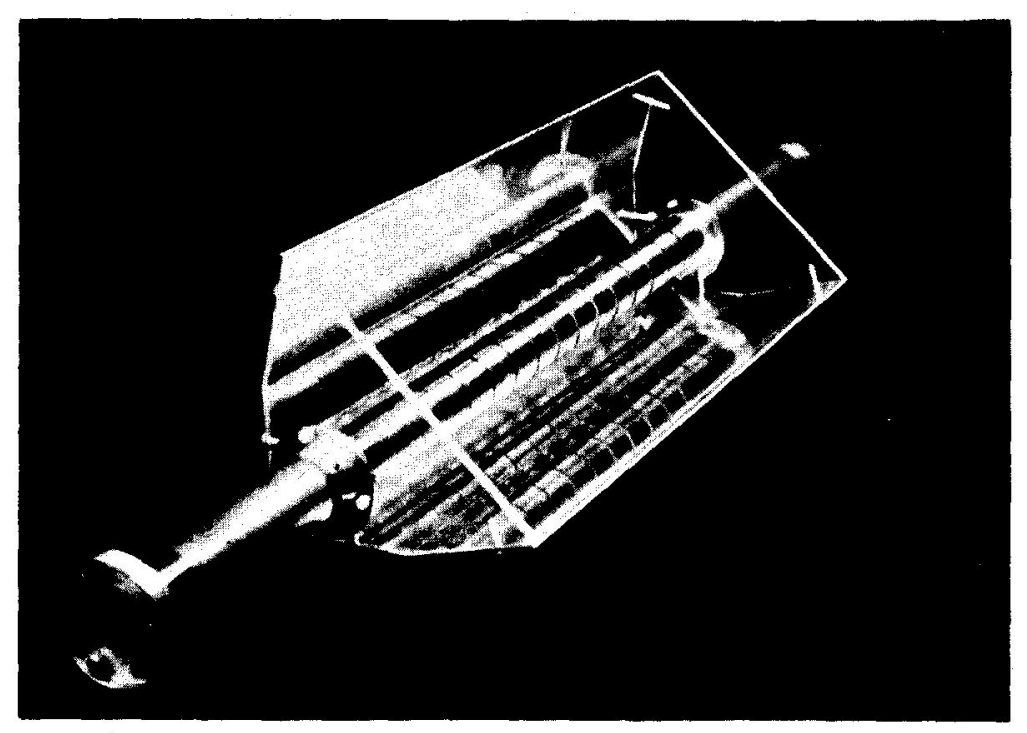

Fig. I X-band radar antenna with tubular feed:

The present paper summarises a computer-aided design procedure for a class of linear travelling-wave arrays based on circular waveguide excited in the $\mathrm{TM}_{\mathrm{O}}$-mode. Owing to their geometrical simplicity, theoretical design of these tubular arrays can embrace mutual coupling between gaps, finite wall thickness, and other realistic features not easily included in conventional slot-array designs without resorting to empirical slot data, lengthy try-and-tune procedures, or repeated bench tests. 


\section{PRINCIPLE OF DESIGN}

Various design procedures realising a prescribed aperture field by a sequence of small matched or unmatched microwave radiators on a common waveguide have been given in the last twenty-five years. The novel feature is application of an elemental radiator whose electrical properties can be precisely theoretically related to its physical dimensions, namely, the circumferential gap in a circular waveguide - Fig. 2. Its radiation efficiency and scattering parameters can be controlled by variation of the gap width. In this way, the prescribed amplitude distribution along the aperture can be set up by an array of gaps of individually chosen widths.

The proper phase progression along the aperture is achieved by locating the gaps suitably along the tube. Being neither matched nor purely resistive, the gaps must have variable interspacings even for a linear phase distribution over the aperture. Therefore, the array is profitably designed by a computer iteration procedure, which may fully exploit the accurate scattering matrix available for the radiating gap [1], and take into account internal reflections in the waveguide as well as external mutual coupling in the aperture.

\section{DESCRIPTION OF GAP PROPERTIES}

The inhomogenous integral equation for the gap field caused by an incident $\mathrm{TM}_{01}$-mode in the structure shown in Fig. 2 was solved by an asymptotic method relating the gap to the planar slit configuration indicated in Fig. 3. From the gap field, scattered and radiated fields can be derived [2].

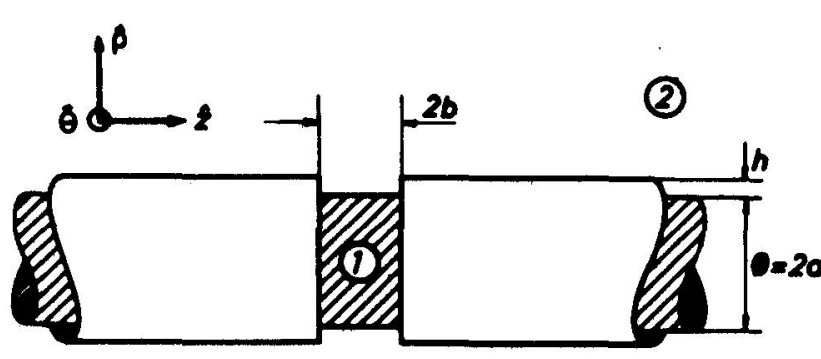

Fig. 2 Elemental radiator: Gap in tube loaded with dielectric of permittivity $\varepsilon_{\mathrm{r}}$

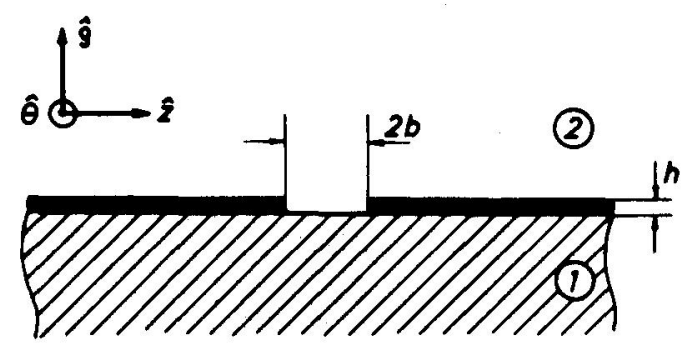

Fig. 3 Corresponding planar slit backed by semiinfinite dielectric

It was found that accurate results for a range of moderate gap widths can be calculated using planar-slit admittance formulae corrected with a perturbation function $\delta(k a, \varepsilon)$ which is independent of the gap width $2 b$. Once $\delta$ has been numericaliy evaluated for a given feeding waveguide at a fixed design frequency, the coupling parameters belonging to any array of gaps in this guide can be speedily sampled from the planar configuration. This simplifies the iteration procedure in array design considerably.

Fig. 4 shows calculated and measured variations of complex reflection coefficient of a gap in Teflon-loaded tube, for gap widths in the interval $0<b / a<0.2$. With the reference plane in the symmetry plane of the gap, and time factor exp (-iwt), the gap is seen to be capacitive in this interval. The arising phase shifts of a wave traversing the gaps can be met by small individual increments in gap interspacing.

For a realistic thick-walled tube, the radiated power is nearly pro- 


\section{B 3/5:3}

portional to the gap width over a wide range. Thus $b / a$ proves to be a very accurate parameter for coupling control in array design, if only the associated variations of reflection and transmission coefficients are taken into account.



Fig. 4 Complex reflection coefficient of gap in Teflonloaded tube. Gap widths in interval $0<b / a<0.2$. Curve is theoretical, and points are measured in $\mathrm{X}$-band

\section{DESCRIPTION OF COMPUTER PROGRAM}

Array design can be directed on a computer performing changes and translations of the gaps, until the aperture field is in accordance with a prescribed envelope function. The interior transmission-line problem is in principle a standard one, since the scattering parameters for the lossy, mismatched gaps are known functions of the geometrical parameters. A recent discussion of the general constraints involved in the interior problem of travelling-wave arrays may, for instance, be found in [3].

In the present geometry, it is also possible to calculate the external wave travelling along the conductor from a gap [4] and, consequently, mutual coupling between the gaps. The interior coupling problem can thus be solved subject to additional explicit constraints imposed by coupling in the aperture; these effects need not be implicitly included as experimentally found increments in slot conductances.

For a narrow-beam, non-resonant antenna, the design runs as follows: An aperture field envelope is prescribed together with the waveguide parameters $k_{a} a, h / a$ and $\varepsilon_{r}$, the number of gaps in the desired array, and the normalised width $b / a$ of the edge gap next to the terminal load.

The deviations from a uniformly spaced array being moderate, the iteration starts by calculating the external contribution to the gap fields from all other gaps when kept at their proper excitations in an equispaced array. Next, the gap widths are determined recursively from the load end, so as to satisfy the prescribed amplitude distribution and the transmissionline constraints of an equispaced array. Computation time for this step is reduced by the above-mentioned application of formulae belonging to the structure shown in Fig. 3, whenever changes of gap width are involved.

Relaxing then the requirement of gap equispacing, but retaining the found gap widths, the computer translates the radiators along the guide un- 


\section{B 3/5:4}

til the prescribed enevelope of the phase curve has been obtained. Small translations have but little influence on the amplitude realisation previously performed. This is checked by repeating the entire procedure with the newly found array as the starting configuration instead of the uniformly spaced array. Convergence towards a configuration realising the prescribed aperture distribution is very fast. Finally, performance parameters, such as squint angle, power dissipation in terminal load, input SWR, band width, and radiation pattern, are computed for comparison with prescribed antenna specifications. If the result is unsatisfactory, another iteration is executed with different starting data. Otherwise, a workshop write-up with machining instructions appears.

\section{DESIGN EXAMPLE}

The feeding array in the $\mathrm{X}$-band radar antenna displayed in Fig. 1 was designed by an early version of the FORTRAN program in less than 10 seconds. Results for this 15-gap antenna have been reported elsewhere [5]; an upper cross-polarisation level of $34 \mathrm{~dB}$ below the main beam could be realised without field-discriminating structures. Therefore, the sidelobe level $(-2 I d B)$ of the desired pattern was very far from being violated by spurious cross-polarised lobes, contrary to most experiences with unfiltered radiation patterns of inclined-slot arrays in rectangular waveguide.

\section{CONCLUSION}

A dielectric-filled metal tube with a sequence of gaps, excited in the $T M_{01}$-mode, is a natural microwave extension of the familiar concept of linear antennas so extensively treated for $\mathrm{k}_{0} a<<1$. Practical designs of tubular microwave antennas, with their inherently linear polarisation and omnidirectional H-plane patterns, may be carried out on a computer.

Prospective use of these antennas, besides narrow-beam feeds for radar antennas, may be for microwave beacons, airfield transmitters, vertically polarised television transmitters, and similar applications, where omnidirectional horizontal coverage should be combined with a directive elevation pattern.

\section{ACKNOWLEDGEMENTS}

The author would like to thank Professor H. Lottrup Knudsen for steady support and encouragement during and after the study reported here, and Mr. J. Bach Andersen for inspiring discussions.

\section{REFERENCES}

1. J. Arnbak: Analysis and Design of Tubular Travelling-Wave Arrays Based on Circumferential Gaps in Conducting Tube. Dissertation, May 1970, Laboratory of Electromagnetic Theory, Technical University of Denmark.

2. J. Arnbak: Scattering and Radiation from a Circumferential Gap in a Circular Waveguide. Proc. IV Colloquium on Microwave Communication, Budapest, 21-24 April 1970, 3,EF-1, pp 1-10.

3. R.M. Breithaupt and G.C. McCormick: Travelling Wave Arrays of Mismatched Elements. IEEE Trans., 1971, AP-19, pp 5-11.

4. J.B. Andersen: Admittance of Infinite and Finite Metallic Antenna. Radio Sci., 1968, 3, pp 607-621.

5. J. Arnbak: Quasi-Equispaced Slot Arrays with Extremely Low Cross-Polarisation. Electron.Lett., 1970, 6, pp 585-587. 